() OPEN ACCESS

\title{
Seromadesis following total hip resurfacing by aspiration and injection of doxycycline
}

\author{
Adam James Farrier 미 , Jim Holland
}

Trauma and Orthopaedics, Newcastle Upon Tyne Hospitals NHS Foundation Trust, Newcastle Upon Tyne, UK

\section{Correspondence to}

Mr Adam James Farrier; c0062352@newcastle.ac.uk

Accepted 5 March 2021
Check for updates

(C) BMJ Publishing Group Limited 2021. Re-use permitted under CC BY-NC. No commercial re-use. See rights and permissions. Published by BMJ.

To cite: Farrier AJ, Holland J. BMJ Case Rep 2021;14:e241523. doi:10.1136/bcr-2020241523

\section{SUMMARY}

Here, we present an interesting case of seroma following hip resurfacing arthroplasty in a 69-year-old man. During the postoperative recovery, the patient made rapid progress and returned to intense activity within the 6 week period. He subsequently developed further right hip pain and swelling. On further examination and on ultrasound scan, a lateral thigh collection was noted. All inflammatory markers were within normal parameters; clinically, there was no evidence of active infection. On initial aspiration and washout, there was a large sterile haemoserous collection. The patient subsequently underwent further aspiration due to persistent collection. After this a revision procedure was performed in two stages with excision of the seroma cavity superficial to fascia lata. Methicillin-sensitive Staphylococcus aureus was grown on extended cultures which was treated successfully with antibiotics. After the second stage revision to total hip replacement, this cavity then recollected. A further trial of aspiration with injection of $200 \mathrm{mg}$ doxycycline, a known sclerosing agent, was performed. The seroma resolved.

\section{BACKGROUND}

A seroma is a pocket of clear serous fluid that forms within the body after surgery. The fluid is composed of blood plasma and may form following disruption of lymphatic channels and the exudative inflammatory fluid produced from damage to bodily tissue during surgery. ${ }^{1}$ A surgically or traumatically created dead space leads to the accumulation of lymphatic, inflammatory and exudative fluids that prevent tissue adhesion. ${ }^{2}$ Seromas remain a trepid and difficult surgical complication. Different treatment options including external compression, percutaneous aspiration and additional surgical intervention which have all been used with variable success. Accessing the sterile fluid within the cavity percutaneously increases the risk for seeding bacteria into the seroma leading to an infected collection. The use of sclerotherapy in the management of seromas has been reported in small-scale studies and case reports, and has shown strong success with minimal complications. ${ }^{3}$ Any improvement in our ability to treat this challenging complication is of great importance.

\section{CASE PRESENTATION}

Here, we present an interesting case of seroma following hip resurfacing arthroplasty. A 69-year-old motivated and physically active family lawyer presented with osteoarthritis of the right hip. He previously had a successful hip resurfacing as treatment for left hip osteoarthritis without complication. His index right hip resurfacing with an Adept Hip Resurfacing implant (MatOrtho, Leatherhead, UK) was performed in November 2015 by $\mathrm{JH}$, the lead author who has extensive experience in hip resurfacing. This procedure was performed without immediate complication. The immediate postoperative course was uneventful with Tinzaparin prescribed for venous thromboembolism prophylaxis. Advice was given to avoid excessive activity during the postoperative recovery; however, the patient made rapid progress and returned to intense activity within the 6-week period. His increased activity included a return to full-time work and driving after 3 weeks, spinning classes; $30 \mathrm{~min}$ to an hour daily after 5 weeks and a long trip to a wedding by train at around 6 weeks. He felt very confident given his expedient recovery and the successful outcome of the same surgery on the contralateral hip. He subsequently developed further right hip pain and thigh swelling. On further assessment at 7 weeks, a lateral thigh collection was noted.

\section{INVESTIGATIONS}

Radiographs and blood tests were sent. The postoperative anteroposterior (AP) pelvis radiographs was as shown in figure 1 , which was deemed satisfactory. All inflammatory markers including full blood count, erythrocyte sedementation rate (ESR) and $\mathrm{C}$ reactive protein were within normal parameters and clinically, there was no evidence of active infection. In December 2015, an ultrasound was performed identifying a loculated fluid collection

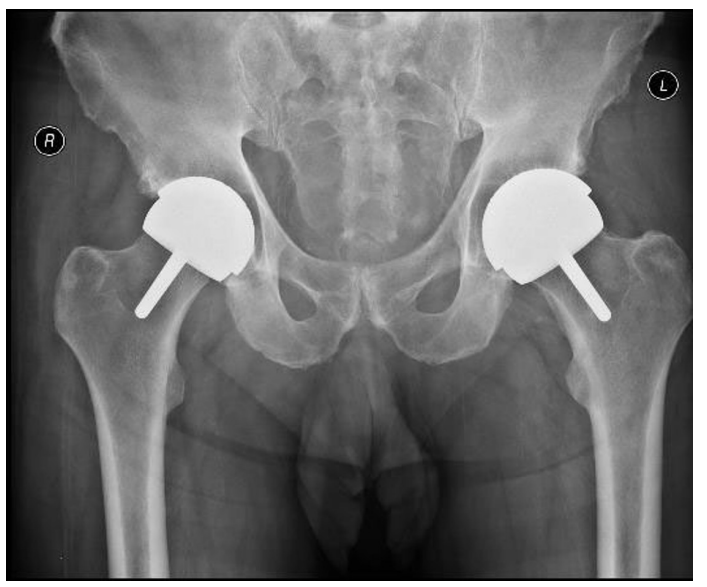

Figure 1 AP pelvis radiograph postinitial right Birmingham hip replacement operation at 2-week followup. 


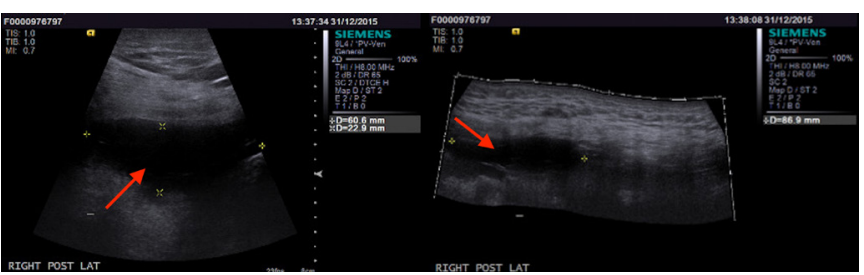

Figure 2 Ultrasound scan showing $86 \times 60 \times 22 \mathrm{~mL}$ fluid collection at 6 weeks post surgery.

measuring $86 \times 60 \times 22 \mathrm{~mm}$ as shown in figure 2. An aspiration was performed with $800 \mathrm{~mL}$ haemoserous fluid removed followed by an open washout with multiple (seven) samples sent intraoperatively. Prophylactic antibiotics moxifloxacin 400 $\mathrm{mg}$ one time a day was commenced pending extended culture results ( 7 days extended anaerobic, mycobacterium and fungi for 21 days). The collection proved to be sterile on extended culture and antibiotics were stopped. Further review in April 2016 showed a persistent collection on examination. Bloods were repeated and the inflammatory markers remained within normal parameters (C-Reactive Protein $(\mathrm{CPR})<5$, Erythrocyte Sedimentation Rate (ESR) 5, White Cell Count (WCC) 7.07). Further, ultrasound scan (USS) showed a persistent collection measuring $76 \times 40 \times 30 \mathrm{~mm}$ as shown in figure 3 . Repeat aspiration was also sterile on extended culture with a negative alphadefensin. Following the second aspiration the distal end of the surgical scar began to leak serous fluid and a sinus developed. In May 2016, after multidisciplinary team discussion despite negative cultures, a two-stage revision surgery was opted for after counselling the patient. During the first stage procedure, a full debridement of the seroma cavity, superficial to fascia lata, was performed and extensive tracking of the seroma down the lateral thigh was observed with multiple samples of fluid and tissue sent for culture and sensitivities. The hip resurfacing was excised and an antibiotic loaded cement spacer (COPAL, Heraeus, Germany) was placed. Intravenous teicoplanin $400 \mathrm{mg}$ twice daily (BD) was commenced as advised by our hospital microbiologists pending extended culture results. The postoperative AP pelvis is shown in figure 4. After extended culture from samples sent at the time of surgery, a low-grade infection with methicillin-sensitive Staphylococcus aureus was identified on three of the seven samples

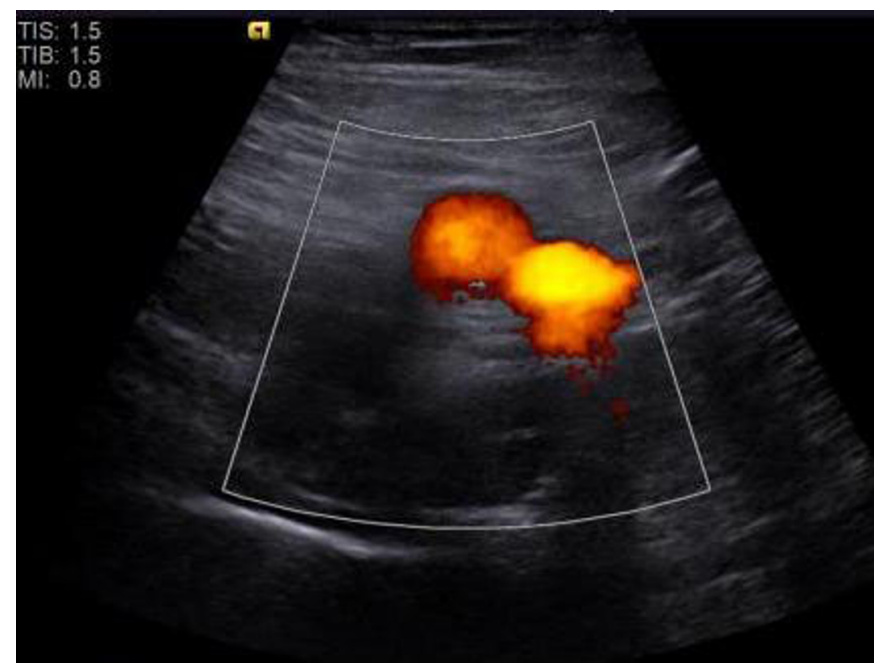

Figure 3 Ultrasound scan showing $76 \times 40 \times 30 \mathrm{~mL}$ fluid collection at 5 months post surgery.

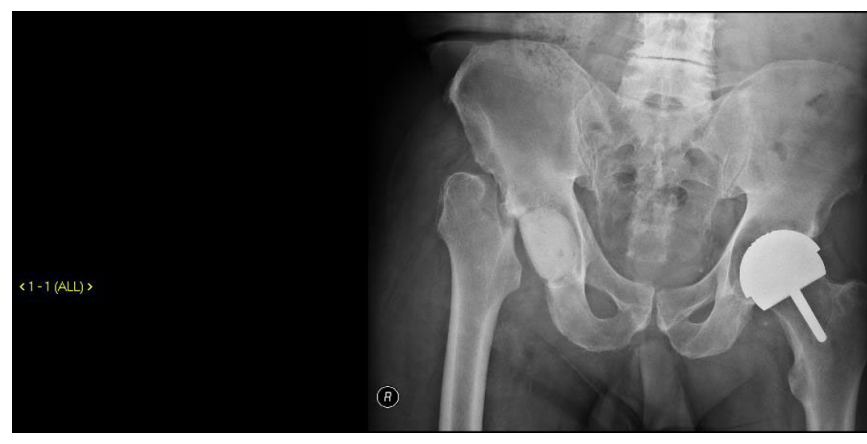

Figure 4 First stage revision showing excision of right hip resurfacing and antibiotic cement spacer.

taken intraoperatively. Antibiotics were stepped down to oral trimethoprim $200 \mathrm{mg}$ two times a day and moxifloxacin 400 mg one time a day for 6 weeks as advised. In August 2016, the inflammatory markers were within normal limits and the soft tissues were quiescent. A second stage revision was performed using a hybrid total hip replacement system; Exeter stem, copal cement and uncemented trident acetabular component with three screws placed into the ileum. Multiple samples of fluid and tissue were taken as per local protocol at the time of second stage surgery which did not grow any organism on extended culture. The postoperative radiograph is shown in figure 5 . Frustratingly at the 6 weeks follow-up in September 2016, the seroma had returned clinically however all inflammatory blood markers remained within normal limits. A close surveillance strategy was opted for after discussion with the patient. In January 2017, the seroma persisted, measuring $41 \times 6 \times 11 \mathrm{~cm}$ on USS (figure 6). In June 2017, a further aspiration was attempted at the patients request with over $1 \mathrm{~L}$ of fluid aspirated which proved to be sterile on culture (figure 7 ). The seroma then recollected (figure 8).

\section{TREATMENT}

After further discussion with our plastic surgical colleague, a further aspiration was performed in theatre with the instillation of $200 \mathrm{mg}$ doxycycline. This was discussed with the hospital formulary committee who, based on literature evidence for its use, approved this non-formulary use for this case. A single dose of doxycycline was used and no further treatment was required. Finally, with great relief, as of May 2018 the seroma had fully resolved with no palpable seroma identified clinically.

\section{OUTCOME AND FOLLOW-UP}

The patient underwent complex reconstructive surgery due to difficulty managing the seroma around the hip. At the time of

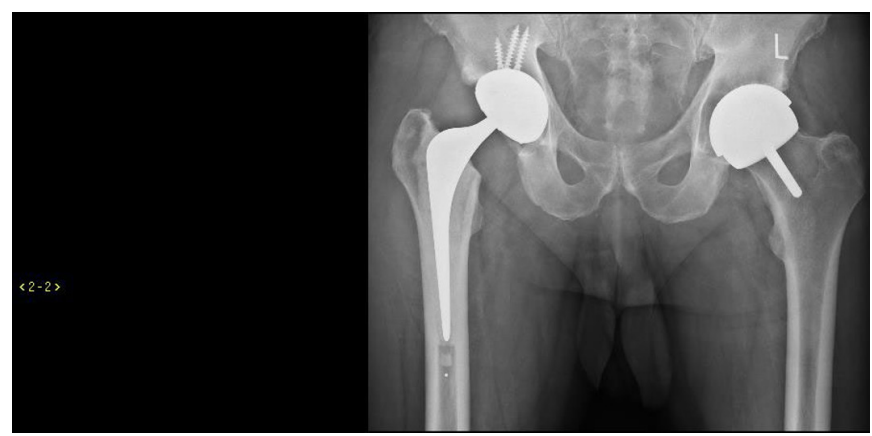

Figure 5 Postoperative radiograph after second stage revision August 2016. 


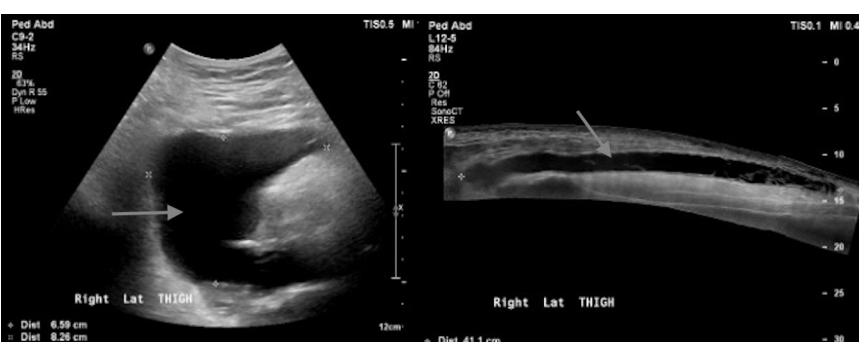

Figure 6 Ultrasound scan showing seroma measuring $41 \times 6 \times 11 \mathrm{~cm}$ tracking down lateral thigh January 2017.

writing, he remains independently mobile, is still working full time and he continues with his spinning classes with a satisfactory outcome from a complex complication. The seroma remains fully resolved.

\section{DISCUSSION}

A seroma is a pocket of clear serous fluid that forms within the body after surgery. A surgically or traumatically created dead space leads to the accumulation of lymph, inflammatory and exudative fluid which prevents tissue adhesion. ${ }^{1}$ The fluid is composed of blood plasma from leaky vessels, disrupted lymphatic channels and the exudative inflammatory fluid produced from damaged cells. ${ }^{2}$ Seromas remain a trepid and difficult surgical complication. Different treatment options include external compression, percutaneous aspiration and additional surgical interventions with varied success. In this case, there may have been an additional inflammatory exudate due to fine element wear debris produced from the metal-on-metal hip resurfacing implant. This may have been exacerbated by an early, rapid progression to intense physical activity during the postoperative period. Seromas remain a trepid and difficult surgical complication. Current treatment options include compression, percutaneous aspiration and possible additional surgical interventions. Accessing the sterile fluid within the cavity poses a risk for contaminating the seroma with commensal organisms resulting in infection. The use of sclerotherapy in the management of seromas has been reported in small scale studies and case reports, and has shown strong success with minimal complications. ${ }^{3}$ In this case, the initial aspiration and washout of the early postoperative haematoma collection did not succeed in preventing the seroma formation. Furthermore, the open washout and repeat aspiration, though negative for organisms on tissue culture, led to the formation of a small sinus and an infected seroma. This ultimately required two-stage revision surgery given the likely communication with the hip resurfacing implant. Despite excision of the pseudo-capsule that had formed during the second stage revision total hip replacement, the seroma recollected.

Tetracyclines in solution form are used topically for chemical pleurodesis in chest surgery. ${ }^{4}$ Doxycycline is a tetracycline antibiotic. Some studies have reported successful topical use of

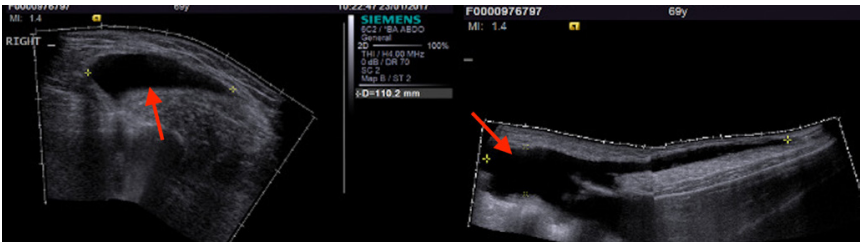

Figure 7 Ultrasound scan June 2017—over $1 \mathrm{~L}$ clear fluid aspirated.

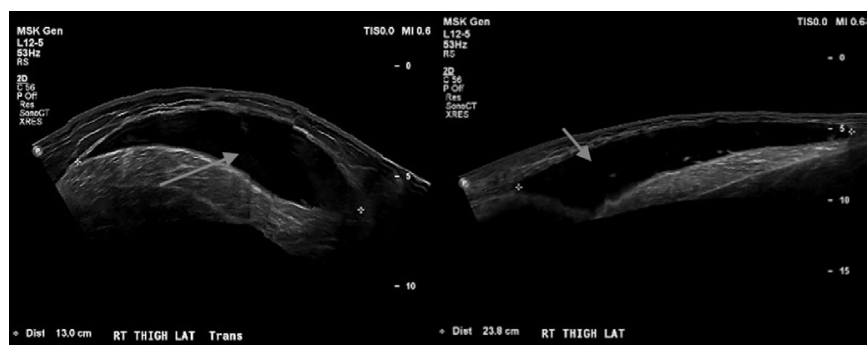

Figure 8 Ultrasound scan September 2017-over 1 L clear fluid aspirated.

tetracyclines in solution as a treatment in seroma, taking advantage of their sclerosing effect in cases of reconstruction following breast surgery, abdominal and hernia surgery. ${ }^{5}$ Prophylactic use of doxycycline has been attempted as prophylaxis in groin hernia repair although this is of no proven benefit. ${ }^{7}$ The common adverse effects of chemical pleurodesis are pain, fever, and gastrointestinal symptoms. ${ }^{8}$ No such adverse effects were observed in this case. Tetracycline has been demonstrated to increase growth factor-like activity in mesothelial cells exposed to tetracycline. This leads to fibroblast proliferation and consequently fibrin formation that closes the dead space present in a seroma. ${ }^{9}$ In addition, the use of doxycycline in seroma provides local delivery of an antibiotic commonly used for skin and soft tissue infections; due to its efficacy against Staphylococcus aureus including methicillin-resistant Staphylococcus aureus. There has also previously been a reported case of successful seromadesis in breast surgery using doxycycline while erythromycin has been used in seromadesis following hip replacement suggesting that treatment is not limited to doxycycline. ${ }^{10} 11$

\section{Learning points}

It is crucial to exclude infection in arthroplasty-associated seroma treatment.

- Multidisciplinary team involvement is fundamental.

- Doxycycline is a safe and potentially curative treatment for seroma around the hip.

\section{Twitter Adam James Farrier @farrier_adam}

Contributors All authors contributed to data collection, writing and editing of this manuscript.

Funding The authors have not declared a specific grant for this research from any funding agency in the public, commercial or not-for-profit sectors.

Competing interests None declared.

Patient consent for publication Obtained.

Provenance and peer review Not commissioned; externally peer reviewed.

Open access This is an open access article distributed in accordance with the Creative Commons Attribution Non Commercial (CC BY-NC 4.0) license, which permits others to distribute, remix, adapt, build upon this work non-commercially, and license their derivative works on different terms, provided the original work is properly cited and the use is non-commercial. See: http://creativecommons.org/ licenses/by-nc/4.0/.

\section{ORCID iD}

Adam James Farrier http://orcid.org/0000-0003-1964-9822

\section{REFERENCES}

1 Sood A, Kotamarti VS, Therattil PJ, et al. Sclerotherapy for the management of Seromas: a systematic review. Eplasty 2017;17:e25.

2 Janis JE, Khansa L, Khansa I. Strategies for postoperative seroma prevention: a systematic review. Plast Reconstr Surg 2016;138:240-52. 
3 Al Daoud F, Thayer A, Sachwani Daswani G, et al. Management of chronic abdominal wall seroma with doxycycline sclerotherapy using a negative pressure wound therapy system KCI-V.A.C.Ulta' ${ }^{\mathrm{TM}}$-A case report. Int J Surg Case Rep 2018;51:25-8.

4 Kilic D, Akay H, Kavukçu S, et al. Management of recurrent malignant pleural effusion with chemical pleurodesis. Surg Today 2005;35:634-8.

5 Nichter LS, Morgan RF, Dufresne CR, et al. Rapid management of persistent seromas by sclerotherapy. Ann Plast Surg 1983;11:233-6.

6 Sitzmann JV, Dufresne C, Zuidema GD. The use of sclerotherapy for treatment of postmastectomy wound seromas. Surgery 1983;93:345-7.
7 Turk E, Karagulle E, Coban G, et al. Effect of topical tetracycline on seroma formation in the Lichtenstein technique: a prospective randomized study. Int Surg 2014;99:147-52.

8 Shaw P, Agarwal R. Pleurodesis for malignant pleural effusions. Cochrane Database Syst Rev 2004:CD002916.

9 Antunes G, Neville E, Duffy J, et al. BTS guidelines for the management of malignant pleural effusions. Thorax 2003;58(Suppl 2):ii29-38.

10 Ramkumar A. Doxycycline sclerotherapy to manage seroma following breast cancer surgery. Indian J Surg Oncol 2020;11:23-4.

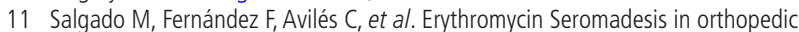
surgery. J Orthop Case Rep 2016;6:62016:92-4.

Copyright 2021 BMJ Publishing Group. All rights reserved. For permission to reuse any of this content visit

https://www.bmj.com/company/products-services/rights-and-licensing/permissions/

BMJ Case Report Fellows may re-use this article for personal use and teaching without any further permission.

Become a Fellow of BMJ Case Reports today and you can:

- Submit as many cases as you like

- Enjoy fast sympathetic peer review and rapid publication of accepted articles

- Access all the published articles

Re-use any of the published material for personal use and teaching without further permission

\section{Customer Service}

If you have any further queries about your subscription, please contact our customer services team on +44 (0) 2071111105 or via email at support@bmj.com.

Visit casereports.bmj.com for more articles like this and to become a Fellow 